\title{
A Trajetória de Adoção de Uma Criança por um Casal de Lésbicas
}

\author{
Mário Augusto Tombolatoo,"*, Ana Cláudia Bortolozzi Maia ${ }^{2}, \&$ Manoel Antônio dos Santos ${ }^{1}$ \\ ${ }^{1}$ Universidade de São Paulo, Ribeirão Preto, SP, Brasil \\ ${ }^{2}$ Universidade Estadual Paulista “Júlio de Mesquita Filho”, Bauru, SP, Brasil
}

\begin{abstract}
RESUMO - Este estudo de caso objetivou conhecer o modo de acesso à parentalidade e analisar a trajetória de adoção na perspectiva de um casal de lésbicas. A entrevista semiestruturada e o questionário foram aplicados a um casal de mulheres, e os dados foram submetidos à análise temática. Os resultados mostram o percurso da adoção marcado por dois momentos: a luta do casal para afirmar a legitimidade do desejo e direito de se tornarem mães, e a surpresa com os rumos tomados pelo processo. A guarda foi concedida desde o início como definitiva, fato incomum nos casos de adoção, mas não em situações de crianças com deficiências. As cônjuges enfrentaram preconceito e discriminação da parte de alguns profissionais e o superaram graças à obstinação, somada ao fortalecimento do enlace afetivo estabelecido com a criança fragilizada.
\end{abstract}

PALAVRAS-CHAVE: poder familiar, adoção, relações mãe-filho, homossexualidade feminina, homofobia

\section{The Adoption of a Child by a Lesbian Couple}

\begin{abstract}
This case study aimed to analyze the access to parenthood and the adoption process by a lesbian couple. A semi-structured interview and a questionnaire were used with both women, and the data were subjected to thematic analysis. The findings reveal that the adoption was marked by two stages: the couple's struggle to assert the legitimacy of their desire and their right to become mothers, and the surprise at how the process unfolded. From the start, custody was awarded as a definitive decision, which is an unusual ruling in cases of adoption, but not in circumstances involving disabled children. The couple had to deal with prejudice and discrimination from professionals but were able to overcome such challenges due to their persistence and the strong bond they established with the vulnerable child.
\end{abstract}

KEYWORDS: homosexual parents, adoptive parents, mother child relations, lesbianism, homosexuality (attitudes toward)

Uma aura de invisibilidade ainda paira sobre as famílias compostas por mães lésbicas e pais gays. É restrito o conhecimento sobre as condições concretas em que esses casais - ou famílias - estão vivendo e gerindo as suas vidas e as de seus/suas filhos (as). A Psicologia no contexto brasileiro, pouco tem se dedicado a desvelar as condições de vida dessas mulheres e desses homens, que nem sempre declaram abertamente sua condição homossexual por temerem represálias ou discriminação (Moscheta, 2004; Uziel, 2007).

Os estudos sobre adoção de crianças na realidade brasileira pouco contemplam as particularidades da homoparentalidade e da diversidade sexual (Fonseca, 2002). A literatura acerca da adoção por indivíduos ou casais homossexuais é incipiente (Amazonas, Veríssimo, \& Lourenço, 2013; Cecílio, Scorsolini-Comin, \& Santos,
2013). Há escassas investigações que focalizam a experiência da maternidade em mães adotivas heterossexuais (Sonego \& Lopes, 2009), além disso, no contexto da maternidade lésbica, os limitados estudos existentes abordam a parentalidade biológica (Corrêa, 2012; Martinez, 2011; Silva, 2013). Com isso, justifica-se a necessidade imperiosa da realização de pesquisas que contribuam para elucidar e discutir a temática da experiência de mães adotivas lésbicas.

Segundo a Secretaria Especial de Comunicação Social do Senado Federal (maio, 2013), o processo de adoção no Brasil envolve determinadas etapas e exigências: o interessado em adotar deve ser maior de 18 anos; e é necessário o cadastro com informações e documentos pessoais, antecedentes criminais e judiciais na Vara da Infância e Juventude. Posteriormente, o juiz analisa o pedido a partir dos pré-requisitos legais. Os candidatos

\footnotetext{
*E-mail: marioaugt@hotmail.com

Apoio: Fundação de Amparo à Pesquisa do Estado de São Paulo - FAPESP (Processos: 2012/13570-7 e 2015/09173-0).

- Submetido: 11/09/2015; Revisado: 09/05/2016; Aceito: 12/08/2016.
} 
habilitados são convocados para entrevistas e, se aprovados, passam a integrar o cadastro nacional, que segue à ordem cronológica de classificação. Quando a criança ou o adolescente está apto à adoção, o adotante inscrito no cadastro é convocado. O prazo médio para o processo de adoção é de um ano, porém, se o processo contiver algum conflito, pode se estender por anos.

$\mathrm{Na}$ sociedade ocidental contemporânea, a família é considerada a mais comum das instituições na qual convivem os indivíduos, sendo um núcleo organizador a partir do qual se estruturam e se transmitem os valores mais importantes da nossa cultura (Lévi-Strauss, 1982; Oliveira, 2011; Rodriguez \& Paiva, 2009). É amplamente reconhecido que a instituição familiar passa por variadas transformações ao longo do tempo e, por isso, não se deve apenas considerar a existência de uma única forma de organização familiar. As diferentes configurações familiares que têm ganhado visibilidade ao longo da história vêm, cada vez mais, dilatando o significado de família. Os diversos arranjos familiares não devem ser entendidos como decorrentes de uma crise na instituição familiar, mas como reflexo das recorrentes mudanças na sociedade e nas concepções do modo como se vive e se entende a família (Araújo, Oliveira, Sousa, \& Castanha, 2007; Oliveira, 2011).

Apesar dessas considerações, o modelo familiar ainda reconhecido e socialmente esperado é ainda restrito ao enquadre nuclear-monogâmico, que é organizado a partir da união entre casais heterossexuais (Rodriguez \& Paiva, 2009). Essa ideologia de modelo familiar norteia, por exemplo, as práticas socioeducacionais e atua, na maioria das vezes, segregando as outras organizações familiares que divergem desse imaginário social.

Passos (2005) pontua que as novas formas de "ser família" devem ser compreendidas, principalmente, segundo a ética que considera as relações e demandas afetivas dos sujeitos nelas envolvidos. Nesse sentido, a ética é baseada nas diferentes formas de conjugalidade, parentalidade e filiação que compõem o contexto familiar fundamentado em laços afetivos. Tais princípios éticos adviriam não mais das normas políticas e culturais que constituem a ordem familiar patriarcal, mas das novas concepções que abarcam a importância das relações de afeto nas novas famílias. Nesse sentido, "se o parentesco é uma ordem simbólica, pode ser ressignificado. Família tem a ver com grupo de pertencimento, sendo um conceito móvel e polissêmico" (Oliveira, 2011, p. 356).

Segundo dados divulgados pelo Instituto Brasileiro de Geografia e Estatística (IBGE), o Censo de 2010 revelou que existem no Brasil mais de 60.000 casais homossexuais. Foi a primeira vez que o governo brasileiro instaurou a preocupação com a visibilidade e quantificação do número de casais homossexuais no país (Lauriano \& Duarte, 2011). Sabe-se que "a materialização das uniões homoafetivas já ocorre há muito no Brasil. Entretanto, a falta de formalização desta união é que não permitia às pessoas nesta condição gozar da segurança jurídica a que todo cidadão brasileiro tem direito" (Pozzetti \& Silva, 2013, p. 108). Muitas vezes, os direitos parentais dos homossexuais têm sido defendidos a partir do argumento de que a orientação homossexual também é compatível com o exercício da parentalidade. Nesse sentido, são reconhecidas as diversas referências à estudos científicos que alegam o bem-estar familiar e a não influência da orientação homossexual dos pais na definição da orientação sexual dos filhos (Golombok, 2015; Teixeira Filho, Toledo, \& Godinho, 2007; Golombok et al., 2003).

Em maio de 2011, o Supremo Tribunal Federal (STF) brasileiro declarou o reconhecimento da união estável para casais do mesmo sexo, desse modo legitimando-os juridicamente como entidade familiar. Dois anos após esse acontecimento, em maio de 2013, durante a $169^{\text {a }}$ Sessão Plenária do Conselho Nacional de Justiça (CNJ) foi aprovada a resolução que habilita a celebração de casamento civil, ou de conversão de união estável em casamento para casais do mesmo sexo (STF, 2013). Sendo assim, a atual legislação da Constituição Brasileira permite aos casais homossexuais a possibilidade de casamento civil, resguardando os seus direitos humanos, civis, sociais e políticos. A legislação nacional vem ao encontro da necessidade de adaptação às mudanças ocorridas na vida da sociedade, considerando a dimensão dinâmica e complexa das relações sociais e familiares.

Verifica-se na prática, um contingente significativo de uniões conjugais estabelecidas por pares homossexuais, todavia, no que concerne ao direito à adoção de crianças por esses pares, a legislação brasileira não possui uma norma jurídica que permita ou impeça, de forma explícita, essa prática (Haag, 2007; Oliveira, 2011; Pozzetti \& Silva, 2013; Zambrano, 2006). Embora se reconheçam determinados casos em que a adoção de crianças foi concedida para ambos os membros do casal, "no Brasil, é mais comum encontrar famílias homoparentais com filhos que são fruto de relacionamentos heterossexuais anteriores" (Rodriguez, 2012, p. 17). Ao considerar essas questões, o presente estudo objetivou conhecer o modo de acesso à parentalidade e analisar a trajetória de adoção na perspectiva de um casal de mulheres lésbicas.

\section{MÉTODO}

Trata-se de um estudo qualitativo, descritivo e exploratório, realizado segundo os fundamentos do estudo de caso único (Stake, 2005). Existem seis preceitos básicos para a produção de um estudo de caso, que são: (a) definir o caso a partir da conceituação do objeto; (b) delimitar a questão a ser investigada; (c) utilizar referencial (is) teórico (s) para compreensão do objeto, entretanto, não se limitando a ele(s); (d) executar a articulação dos métodos, 
das fontes, das técnicas de análise e das teorias; (e) atentar-se às interpretações alternativas para os dados; e f) elaborar, quando plausível, asserções e generalizações (Stake, 2005; Tombolato, Maia, Uziel, \& Santos, 2018).

\section{Participantes}

Participou deste estudo um casal de mulheres lésbicas que adotou uma criança. Os nomes próprios das participantes foram substituídos por nomes de pintoras brasileiras, e o nome próprio da criança pelo nome de uma escritora brasileira. Os demais nomes, locais e determinadas características que apareceram nos depoimentos também foram mascarados ou omitidos, de modo a manter a confidencialidade dos dados e preservar o sigilo e a identidade das entrevistadas. $\mathrm{Na}$ Tabela 1 estão descritos os dados sociodemográficos das participantes.

O casal se conheceu na formatura (da faculdade) de Tarsila, época em que Adriana coabitava com sua antiga namorada. Tomaram a decisão de morar juntas devido às brigas constantes que Tarsila enfrentava em sua família em decorrência de sua orientação sexual, somada ao fato de Adriana ter um apartamento próprio. O hiato de tempo desde que se conheceram até irem morar juntas foi de um ano. Decorridos oito meses de coabitação, elas assinaram a certidão de união estável. A família de Adriana esteve presente nessa celebração. Da família de Tarsila, o único representante foi o pai, pois os demais familiares não aceitavam a relação conjugal entre duas mulheres. A rejeição familiar é um tema recorrente nas trajetórias de vida das

Tabela 1

Perfil do Casal Participante do Estudo

\begin{tabular}{lcccc}
\hline Nome & $\begin{array}{c}\text { Idade } \\
\text { (anos) }\end{array}$ & $\begin{array}{c}\text { Tempo de } \\
\text { relacionamento }\end{array}$ & Escolaridade & $\begin{array}{c}\text { Situação } \\
\text { ocupacional }\end{array}$ \\
\hline Tarsila do Amaral & 27 & 3 anos e 2 meses & Pós-graduação & Microempresárias \\
Adriana Varejão & 33 & Ensino Superior & $6.850,00$ \\
\hline
\end{tabular}

\section{PROCEDIMENTO}

\section{Coleta de dados}

Seleção e contato com os participantes. A identificação de potenciais participantes e o convite para participação no estudo decorreram dos contatos com especialistas nacionais da temática e de integrantes da rede pessoal dos pesquisadores, que indicaram famílias homoparentais. Das 13 famílias identificadas preliminarmente, cinco aceitaram participar de um projeto de pesquisa mais amplo, que visou investigar as vivências familiares de casais homossexuais com filhos (as). Dentre essas famílias, três eram compostas por casais femininos e duas por casais masculinos. A família escolhida para este estudo de caso era a única pessoas homossexuais (Silva, 2013). Tarsila e Adriana formam um casal há pouco mais de três anos e trabalham juntas em um negócio próprio. Na época da entrevista, em 2013, a filha aqui designada como Nísia Floresta, tinha dois anos e seis meses de idade.

\section{Instrumentos}

Para coleta de dados foram utilizados dois instrumentos: o Questionário de Perfil Socioeconômico de Famílias Homoparentais e o roteiro de entrevista semiestruturada "Conhecendo as Famílias Homoparentais". A construção dos dois instrumentos, pelos pesquisadores, fundamentouse em três procedimentos: (1) os instrumentos foram delineados a partir das informações sistematizadas pela revisão bibliográfica; (2) Foram submetidos a três juízes - professores doutores, especialistas na temática em que o projeto se insere, para avaliação da pertinência das questões propostas e necessidade de posteriores adequações, conforme as sugestões do comitê de especialistas; (3) Realizou-se uma entrevista-piloto para testar a adequação dos instrumentos aos objetivos da pesquisa.

O Questionário de Perfil Socioeconômico de Famílias Homoparentais contém questões abertas e fechadas acerca da realidade socioeconômica das famílias de casais homoparentais. O roteiro de entrevista semiestruturada "Conhecendo as Famílias Homoparentais" aborda os temas: história do relacionamento amoroso do casal, famílias de origem, escolha e processos da parentalidade, rotina familiar, situações de preconceito enfrentadas e rede de apoio social. 
Análise de dados. Os dados foram analisados por meio da análise temática proposta por Braun e Clarke (2006), percorrendo seis etapas: a) familiarização com os dados, b) elaboração de códigos iniciais, c) busca por temas, d) revisão dos temas, e) definição e nomeação dos temas, e f) elaboração do relatório da pesquisa. A interpretação e discussão foram produzidas de acordo com a fundamentação teórica derivada da literatura da área.
Aspectos éticos. Este estudo foi desenvolvido conforme as diretrizes da Resolução 466/12 do Conselho Nacional de Saúde, que regulamenta as pesquisas com seres humanos (Brasil, 2012). O projeto de pesquisa foi submetido à Plataforma Brasil/CEP e obteve o parecer consubstanciado de aprovação em abril de 2013 (CAAE 06439812.0.0000.5398). As participantes leram e assinaram o Termo de Consentimento Livre e Esclarecido (TCLE).

\section{RESULTADOS E DISCUSSÃO}

Foram elaborados quatro núcleos temáticos, que serão apresentados e discutidos a seguir.

\section{Convivência Familiar, Relacionamento Amoroso e Avanço da Idade: As Motivações para Ser Mãe}

No relato de Adriana, notamos que o desejo de ser mãe emergiu desde que sua cunhada ficou grávida, há nove anos. A concretização desse desejo começou a se realizar a partir do relacionamento com Tarsila, que também queria ter um filho. Adriana, então com 32 anos, sinalizou à companheira que gostaria de ter um filho logo, por considerar o avançar de sua idade e a preocupação de ser "mãe" da criança e não "vó".

O meu interesse vem desde que a minha cunhada ficou grávida da minha sobrinha. A minha sobrinha vai fazer oito anos. Na época que ela tava grávida eu queria muito ter um filho, ou engravidar ou adotar. Só que dai [...] naquele momento não dava certo. Dai passou a vontade, fiquei um tempo sem pensar em ser mãe, "então tá, deixa pra lá". Até que eu comecei a me relacionar com ela (Tarsila) e ela ficava sempre: "aí, porque eu quero ter um filho, porque eu quero ter um filho". Ai um dia, eu voltando pra casa, (ela) começou: "porque eu quero ter um filho, não sei o quê, tal". Falei assim: "então, tá. Você quer ter um filho, vai ter que ser agora. Porque eu não quero ser vó, quero ser mãe”. Como eu já estou com 32 anos, pra mim tem que ser já. Óbvio, ela deu uma assustada. "Mas já?". Falei assim: "Ah, se a gente vai adotar então, vamos atrás, vamos saber como que é, o que tem que fazer para que isso aconteça, porque normalmente uma adoção demora e pra esperar três, quatro anos pra mim vai ficar tarde". Dai que ela: "então tá, vamos atrás, vamos ver o que a gente pode fazer”. (Adriana)

Embora o desejo de ter filhos tenha sido uma expressão do casal, no relato, evidencia-se que uma das parceiras, simbolicamente, tomou a frente na díade conjugal para a efetivação do projeto da parentalidade (Almeida, 2012). Podemos também refletir que, na população em geral, parece haver um padrão normativo, que leva à idealização da necessidade de ter filhos para que se possa garantir a formação de uma família "normal" e/ou "feliz", e isso também transparece nas expectativas de relacionamento amoroso e familiar homossexual (Uziel, 2007; Vieira, 2011).

\section{Dando Tratos ao Desejo da Maternidade: Conhecendo Abrigos e Crianças}

Tarsila e Adriana comentam que, inicialmente, antes de procurarem o Fórum e se inscreverem no cadastro de adoção, haviam planejado apadrinhar uma criança. Com esse objetivo em mente, visitaram dois abrigos infantis (aqui denominados de Abrigo A e Abrigo B) na cidade em que residem. Segundo elas, no Abrigo B o pedido de apadrinhamento foi indeferido porque provinha de um casal composto por pessoas do mesmo sexo.

Hora que a gente chegou lá (Abrigo B), foi péssimo, porque a gente sabe que existem muitas crianças para ser adotadas e a gente sabe que não anda, as leis não ajudam essas crianças. Mas, quando a gente chegou lá, eles falaram que todas as crianças já tinham família, que não tinha quem a gente... Porque, a princípio, a gente não queria adotar, a gente queria começar a fazer um apadrinhamento [...] Ai, a hora que a gente falou que a gente queria fazer o apadrinhamento, já mudou totalmente, né, a forma de relacionamento. [...] Porque eram duas mulheres. "Como que duas mulheres vão cuidar de uma criança? " [...] Dai eles falaram que não tinha e que não tinha, ponto final. Mas a gente sabia que têm crianças, né? (Tarsila)

O apadrinhamento afetivo é um programa direcionado a crianças e adolescentes que vivem em situação de acolhimento ou em famílias acolhedoras. Tem por finalidade a promoção de vínculos afetivos duradouros entre eles e pessoas da comunidade, denominadas padrinhos e madrinhas. Aquelas que estão em condições de serem apadrinhadas, por vezes, são crianças com deficiências ou doenças crônicas, condições que resultam em chances remotas de adoção. O padrinho ou a madrinha se torna uma referência na vida da criança, mas não recebe a guarda, pois o guardião continua sendo a instituição de acolhimento (Conselho Nacional de Justiça, 2015).

Segundo Farias e Maia (2009), há inúmeros preconceitos disseminados entre os profissionais das instituições que cuidam de menores. As atitudes preconceituosas envolvem os casais homossexuais que pretendem assumir crianças, seja em termos de adoção ou de apadrinhamento. No casal em tela, embora não verbalizado, o preconceito foi depreendido pelas participantes devido às atitudes dos profissionais responsáveis 
pelo abrigo. O preconceito levou a uma conduta excludente e discriminatória, que resultou no fechamento das portas da instituição para qualquer possibilidade de diálogo com as participantes. Por outro lado, o fato de os motivos dessa ação não serem explícitos, resultou em poucas alternativas de interlocução, que poderiam contribuir ao menos para o esclarecimento das posições antagônicas em jogo.

O relato de Tarsila evidencia uma reação imediata de rejeição à possibilidade de adoção quando se tratam de duas mulheres. No entanto, o protagonista dessa ação não fica claro. Segundo a participante, "eles falaram”, mas não há uma especificação de qual funcionário enunciou exatamente essa determinação: coordenador do abrigo, psicólogo, assistente social? De qualquer forma, podemos questionar: em que concepções, conhecimentos e justificativas estaria fundamentada a atitude dos profissionais do abrigo? (Farias \& Maia, 2009). E como são afetadas as mulheres vítimas de discriminação nesse processo? (Goldberg, Kinkler, Moyer, \& Weber, 2014). Se a atitude preconceituosa não pode ser explicitada, devido aos constrangimentos que sua manifestação franca e direta causaria, a parte prejudicada não pode se defender.

De acordo com as participantes, no Abrigo A elas foram bem acolhidas como casal, principalmente em decorrência de o diretor da instituição ser homossexual assumido e pelo fato da política do abrigo considerar de forma igualitária as diversas configurações familiares. Foi neste Abrigo A que conheceram Nísia, que viria a ser sua filha.

Ai chegando no Abrigo A, a gente se apresentou como um casal e falou que queria conhecer alguma criança para apadrinhar, com interesse de adoção. Ai lá foi totalmente ao contrário. Principalmente porque o diretor de lá é homossexual, então eles entendem que, qualquer família que queira adotar, vai ser bom para a criança. Então dai foi um atendimento espetacular. Eles fazem, a princípio, uma entrevista de qual o perfil de criança que a gente gostaria de ser mãe. E acredito assim, nós duas acreditamos nisso, que se você quer ser mãe, você vai ser mãe de qualquer criança. Não tem que escolher cor, nada disso. (Tarsila)

No primeiro momento, podemos pensar que a relação entre o diretor e as candidatas à adoção poderia, em tese, favorecer uma concepção favorável à causa por identificação e/ou simpatia. No entanto, é importante ressaltar que o direito à adoção e a avaliação das condições de qualquer pessoa para aceder à posição de adotante independem da esfera pessoal e particular do profissional que avalia o caso, que deve atuar com imparcialidade, a partir dos princípios reguladores de seu cargo e/ou de sua profissão.

Além disso, ainda neste excerto de fala é possível constatar a compreensão de Tarsila e Adriana de que o desejo de ser mãe deve prevalecer em relação às características da criança, desse modo, "qualquer criança", em princípio, poderia suprir esse anseio. Porém, na sequência do relato notamos que o casal, inicialmente, não abriu mão de seu direito de escolha:
Mas a gente colocou que a gente queria menino, né? A princípio, até dois anos. [...] tinha uma criança já com nosso perfil, que era chamada Júlia e tinha dois anos e meio, né? [...] Só que quando a gente conhece as crianças, a gente conhece todas as (outras) crianças, parece um açougue, né? Você escolhe a carne que você quer e leva. Mais ou menos assim que as crianças se sentem lá. (Tarsila)

Nessa fala é possível identificar uma compreensão de que o desejo de ser mãe se impôs na vida das participantes em relação a qualquer tipo de constrangimento que pudessem encontrar pelo caminho. Tanto é verdade que a primeira escolha (deveria ser um menino e de, no máximo, dois anos) pôde se transformar durante o percurso, em virtude das experiências vivenciadas, que levaram o casal a reconfigurar suas predileções iniciais. Outro aspecto a ser ponderado é a situação de acolhimento no abrigo, descrito de maneira crua como um "açougue" humano, onde o consumidor escolhe o produto que deseja levar, segundo a lei da oferta e procura. Essa situação leva a pensar no quanto as crianças podem estar expostas como se estivessem disponíveis em um balcão para atraírem o olhar e o interesse dos eventuais pais/ mães. Estudos nacionais que versam sobre o acolhimento institucional de crianças abandonadas apontam que os candidatos à adoção têm de superar inúmeras barreiras para consumarem seu desejo de adotar (Rossetti-Ferreira et al., 2012; Silva, 2004). Muitas vezes o abrigo é um lugar de acúmulo de carências, no qual falta de tudo ou tudo ainda está por se construir, e essa situação de penúria material (e, por vezes, de empobrecimento relacional e afetivo) fica estampada nos olhos das crianças que recebem as visitas dos pretendentes à adoção (Manzi-Oliveira, 2009). Essa experiência preliminar à adoção também foi marcante para o casal participante deste estudo.

Prosseguindo o relato, o casal revela que, no momento em que foi conhecer Júlia - a criança que mais se aproximava do perfil que almejavam - se depararam com Nísia. Na fala de Tarsila, foi uma situação muito especial, que teve grande significado para sua decisão de adoção (Sonego \& Lopes, 2009).

E quando a gente foi conhecer a Júlia, a Nísia já estava lá. E eu olhei para a Nísia [bebê] e foi amor à primeira vista. Fiquei com ela no colo o tempo inteiro, não soltei, dei leite... A gente ficou uma hora mais ou menos lá. (Tarsila)

\section{Caminhos da Adoção: O Enlace entre Mães e Criança é um Percurso Sinuoso}

Após o singular contato com Nísia, o casal se interessou em adotá-la. Com isso, Adriana e Tarsila foram alertadas pela psicóloga do Abrigo A de que precisavam estar inscritas no cadastro de adoção e, portanto, estarem posicionadas na fila de pretendentes do Fórum. Essa percepção da necessidade de tramitação e da obediência aos meandros da máquina burocrática, inicialmente, causou desmotivação. Diante desses 
percalços, Tarsila chegou a considerar a inseminação artificial como alternativa possível para realizar o desejo de ser mãe.

"É impossivel a Nisia ser de vocês" [reproduzindo a fala da psicóloga do Abrigo A]. Ai eu falei: "Mas por que impossivel?" Ai ela falou: "Porque ela vai pra fila do Fórum e vocês não estão nem na fila do Fórum, vocês vieram aqui direto e o fórum não sabe que vocês querem adotar". Falei: "Então tá, né? Se não é a Nísia, pensei, não é ninguém”. (Tarsila)

Aí ela (Tarsila) falou assim: "Então já que não dá certo, quero fazer inseminação”. Daí ela até ligou pro médico e tudo, marcou uma consulta para sexta-feira seguinte e tal. Só que na quinta, na quinta ou na quarta, eu falei: "Tarsila, já pensou quanto vai ter que gastar pra fazer essa inseminação? Tipo, e o dinheiro que a gente gastaria com essa inseminação pode gastar com uma criança, que já, já está precisando de família". Dai ela desmarcou, ai teve treinamento (no trabalho) que ela foi, eu fiquei o final de semana só, dai que na segunda-feira depois, aí já ligaram pra gente perguntando sobre o negócio da Nísia. Pra mim é, tipo assim, a princípio a Nísia não, não tava, porque sendo realista, tipo não tem como a Nísia estar vindo pra gente. Pelo motivo de ela ser bebê, a gente não ter feito inscrição no Fórum, então a Nísia estava fora de cogitação. (Adriana)

Em seguida, Tarsila relata que Nísia apresentava um quadro de desnutrição severa e microcefalia, e que, coincidentemente, já havia estudado essa temática na época de sua graduação universitária. Essas características de Nísia foram determinantes para que nenhuma pessoa do cadastro de adoção do Fórum tivesse interesse em adotá-la. Sendo assim, o abrigo entrou em contato com Adriana e Tarsila a fim de averiguar o real interesse pela adoção.

A Nísia, ela ficou dez meses com a mãe dela, então ela ficou desnutrida, uma desnutrição muito forte, muito severa. E isso ocasionou um, um diagnóstico de microcefalia nela. Então, o que aconteceu? Ela foi para o Fórum, com esse perfil, então nenhuma família quis a Nísia, porque tinha microcefalia e desnutrição, né? E o mundo é tão redondinho que eu fiz o meu TCC (trabalho de conclusão de curso) de crianças com microcefalia, então eu já sabia o que podia acontecer e o que não podia acontecer. Quando a gente viu a Nisia, a gente sabia que ela tinha alguma coisa, mas para mim naquele momento foi intenso, que eu não queria nem saber o que ela tinha, né? E dai, na segunda-feira, a psicóloga me ligou: "Oi, Tarsila, aqui é a psicóloga, a Nísia foi pro Fórum e nenhuma família quis ela, vocês querem ficar com ela?" (Tarsila)

Apesar de Nísia ser um bebê e, por esse fato, concorrer mais facilmente ao interesse de casais na fila da adoção, seus problemas de saúde colidiam com os interesses das pessoas da fila. Foi esse o fator determinante que favoreceu a disponibilidade de Nísia para a adoção deste casal. Embora o fato tenha sido percebido pelo casal como algo que contribuiu decisivamente para atender aos seus interesses de acesso à maternidade, também evidencia a percepção de
Adriana e Tarsila de que conseguiram a adoção por se tratar de uma criança com necessidades especiais e pela qual outros adotantes não se interessavam.

Uma circunstância delicada em adoção se refere ao acolhimento de crianças com necessidades especiais (Silva \& Cavalcante, 2015). Essa característica, encarada como desvantagem pela maior parcela dos pretendentes à adoção, na verdade foi o que promoveu o enlace simbólico entre mães e filha na situação investigada. Esse achado também foi referido por Otuka, Scorsolini-Comin e Santos (2012).

Um dos motivos que impulsionam os casais a adotarem, pode ser o desejo de cuidar, que tende a se fortalecer pelo contato com uma criança abandonada pelos pais biológicos. $\mathrm{O}$ fato de Tarsila e Adriana desejarem cuidar de um bebê altamente vulnerável favoreceu enormemente a consumação da adoção. É essencial indagar, se, nos casos de crianças debilitadas por alguma condição orgânica, acometidas por doenças infectocontagiosas ou anomalias do desenvolvimento, os óbices e constrangimentos normalmente encontrados por pais e mães homossexuais seriam abrandados. No estudo de Otuka, Scorsolini-Comin e Santos (2012), a criança adotada enfrentou complicações de saúde em seu início de vida. Tais dificuldades não foram sentidas pela mãe adotiva como um peso, todavia como uma situação de enfrentamento e disponibilidade, favorecendo, assim, o processo de acolhimento e amadurecimento gradual da criança.

\section{Tornando-se Mães e Filha:Agora Somos uma Família!}

As narrativas das participantes acerca do processo de adoção de Nísia são entremeadas com comentários emocionados sobre o início de suas vivências como mães.

Que ai nós fomos no mesmo dia lá, ficamos mais um pouquinho com a Nísia, tudo, né? E tivemos que começar a fazer o processo de trás para frente, né? Porque tinha que se inscrever no Fórum, os processos burocráticos a gente teve que fazer. [...] Pra gente foi um choque, porque a gente não estava preparada financeiramente, porque a gente estava abrindo (nome da empresa que são sócio-proprietárias), então não tinha dinheiro pra fazer isso. (Tarsila)

O roteiro seguido pelo casal para consumar o desejo da maternidade não foi um projeto integralmente planejado. $\mathrm{O}$ desejo foi se adaptando às circunstâncias que se apresentavam no momento, amoldando-se ao possível, o que também se percebe em estudos com casais heterossexuais que adotam (Levy \& Féres-Carneiro, 2001). O ter de "começar de trás para frente" parece estar mais relacionado ao contexto da adoção do que ao fato de serem um casal de mulheres. Embora não estivessem financeiramente programadas para serem mães, o desejo da maternidade, somado à especial disponibilidade de adoção de Nísia, atuaram na concretização do acesso à parentalidade. 
Então, não tinha dinheiro pra fazer isso, pra ser mãe, é aquela velha história, né? Não tem que ter, né? Não tem que se programar pra ser mãe, é mãe e ponto, acabou. Tem que ser, tem que ser. (Tarsila)

Dessa maneira, a união e cumplicidade do casal homoafetivo foram os principais ingredientes utilizados como recursos de apoio para prosseguirem nesse desafio.

Aí uma olhou para a cara da outra e falou: "Está bom". [...] Vocês vão começar na terça-feira a fazer adaptação com a Nísia. Aí a gente saiu de lá desesperada, louca, assim, eufórica, né? (Tarsila)

Não tinha cadeirinha, não tinha roupa, não tinha... fralda, não tinha... (Adriana).

A aceleração inusitada do processo mostra que, quando realmente está em jogo o melhor interesse da criança, questões de natureza burocrática e moral se esvanecem, e se imprime um ritmo frenético ao processo. Habitualmente, o processo de adoção é descrito pelos adotantes como moroso, pouco resolutivo e permeado por barreiras (Campos \& Costa, 2004; Weber, 2004). Nessa ocasião, a união e cumplicidade do casal foi o principal recurso com que contaram para se ajustarem rapidamente às novas necessidades e, assim, viabilizarem a adoção. Em uma circunstância tão improvável quanto inaudita, o apoio mútuo mostrou-se essencial na reafirmação do desejo pela parentalidade (Goldberg \& Smith, 2011).

Algumas dessas características da adoção anunciadas pelo casal homoparental dialogam com outras configurações de adotantes - casais heterossexuais, monoparental, tardia (Almeida, 2012; Torres, 2009; Uziel, 2007). Entre essas características, estão: a fase de acolhida e do processo de adaptação da criança; as alterações na dinâmica conjugal após a chegada dos filhos; a construção do vínculo intrafamiliar; entre outras.

Em seguida, Tarsila relata acerca do enfrentamento da delicada situação de saúde de Nísia.

Só que como ela, ela teve esse problema de desnutrição, ela tinha um ano, mas ela estava com um desenvolvimento de quatro, cinco meses, então... (Tarsila)

Era um bebê... (Adriana).

E daí a gente fez isso, [...] pegamos ela, levamos pra APAE, pra fazer a fisioterapia, e lá na APAE a gente encontrou $O$ primeiro obstáculo: "será que realmente a gente quer ser mãe da Nísia?" Porque [...] a fisioterapeuta falou: "Vocês sabem, foi dito pra vocês que ela não vai andar, que ela não vai falar, né? Vocês sabem disso?" Eu falei pra ela, né?: "Quem é você pra falar que ela não vai fazer nada disso?" Principalmente porque eu trabalho com a neurolinguística, então a gente sabe que as coisas, os traumas podem ser resolvidos e as crianças podem evoluir, só elas vão saber, se elas vão, se elas não vão evoluir. Aí a gente continuou ainda levando ela na APAE, algum tempo, enquanto ela estava no Abrigo B. (Tarsila)
A não aceitação do prognóstico reservado emitido pela profissional parece reforçar ainda mais o vínculo afetivo que estava sendo construído com a criança. Não com uma criança qualquer, mas uma criança desacreditada pela maior parte das pessoas do seu ambiente. Uma criança que angaria sentimentos negativos, como apreensão, repúdio e dúvida quanto à viabilidade de ter um futuro promissor. As mães se unem ainda mais para lutar contra esse estigma de fracasso que ronda sua bebê. Tarsila critica veementemente a atuação da fisioterapeuta da APAE. A reação de Tarsila tanto pode se assemelhar à dificuldade emocional de aceitação da deficiência/malformação congênita de um filho (a), tal como aponta a literatura (Nascimento, 2006; Perosa, Silveira, \& Canavez, 2008) quanto à possibilidade de ela questionar e agir ativamente contra um prognóstico fatalista e limitante.

Paralelamente à realização da adaptação do casal com Nísia, ocorria o processo de adoção no Fórum. O depoimento de Tarsila traz características das entrevistas no Fórum.

E no meio desse processo de adaptação, a gente tava com processo no Fórum, que as psicólogas chamaram a gente pra conversar, o que é uma piada, né? Eu achei uma piada a entrevista do Fórum. (...) Por exemplo, uma pergunta que ela fez foi: "Ah tá, vocês querem ser mães da Nísia, e se vocês se separarem?" Aí a gente, né?: "Calma lá... primeiro que se a gente está junta, a gente não vai viver no "e se a gente se separar". Existe essa possibilidade? Até pode existir, hoje a gente vive na certeza de querer ser mãe, e mesmo se a gente se separar, nós vamos continuar sendo mães da Nísia, nós não vamos simplesmente virar uma de cara para a outra e não se ver nunca mais e deixar a criança num meio social perdida, né? (Tarsila)

Ao discorrer sobre a desconfiança dos profissionais do Fórum em relação à coesão do casal e à capacidade de exercer o papel materno, Tarsila se exalta. Pergunta-se: "será que um casal enquadrado na heteronormatividade também é sabatinado dessa maneira?". Ao se sentir discriminada, levanta a bandeira de que um casal homossexual teria qualidades excepcionais que os diferenciam, positivamente, dos casais heterossexuais. Nesse sentido, o estudo realizado por Golombok et al. (2014) indica que o bem-estar parental e a parentalidade são melhores em famílias de pais gays quando comparados a famílias de pais heterossexuais. Além disso, os dados evidenciam que os problemas externalizantes são maiores entre as crianças de famílias heterossexuais em comparação às famílias de pais gays e mães lésbicas.

Porque, além da nossa relação, a gente é mãe, é diferente de ser um pai e uma mãe, né? A gente colocou isso. Porque se tem uma briga de hétero, a gente sabe, existem brigas de gays, lógico. Mas a gente não tem isso, a gente é muito diálogo aberto, a gente conversa, a gente não briga. A PNL (programação neurolinguística) ajuda nisso, a saber mesmo o que a gente quer. Então ela ficou assim pra minha cara, né? Falei: "Porque, se a gente quer ser mãe, a gente sabe das 
responsabilidades que a gente tem e a gente acredita que a gente vai conseguir ser mãe, ser uma das melhores mães. $O$ melhor que a gente pode". Dai ela ficou meio assim. E eu falei pra ela, né? "Como eu tenho a PNL, eu falei, preciso da sua ajuda”, que a gente estava dependendo dela pra poder levar a Nisia. Porque a gente já estava na adaptação, de sete horas da manhã às cinco horas da tarde. Imagina, você fica o dia inteiro com a criança e leva ela embora. Era muito dolorido isso, eu entrava, quase chorava, às vezes. (Tarsila)

Nota-se, nessa fala, o esforço do casal para vencer as barreiras colocadas pelo Judiciário - ou, na melhor das hipóteses, pela convicção de uma psicóloga com poder de decisão ( "a gente estava dependendo dela pra poder levar a Nísia"). No tempo que durou o processo de avaliação, o casal de mulheres não pôde permanecer com a guarda provisória da criança, embora já estivesse se responsabilizando por prover vários cuidados diários.

A principio a gente levava na fisioterapia, depois de duas semanas que a gente começou a ficar com ela de manhã, até à tardezinha, que foram mais duas semanas. [...] Ai eu falei pra Adriana: "A gente não vai mais devolver ela". Ai a Adriana: "Não, mas tem que devolver". Falei: "Não, eu vou ligar lá e falar que a gente não vai mais levar ela embora, que ela já está adaptada no ambiente, eu não vou levar ela embora" (riso). E dai saiu, e foi isso, sábado, domingo, segunda, terça, quarta saiu a guarda. (Tarsila)

Adriana comenta que o período decorrido desde quando conheceram Nísia no abrigo até a autorização da guarda para a adoção foi de um mês. Considerando o tempo habitual dos processos legais de adoção no país, esse é um tempo ínfimo (Almeida, 2012; Costa \& Campos, 2003; Weber, 2004).

Foi um dia antes do nosso um ano de casamento. Que eu até tinha brincado, eu lembro disso porque eu falei: "Ah, nós vamos ganhar um 'presentaço'de casamento!'. Foi no dia 16, saiu a guarda dela. Então, foi nem um mês, outubro, novembro. Menos de um mês. Então a gente não teve nem os nove meses de preparo. (Tarsila)

A alusão simbólica aos nove meses de gestação mostra que, no imaginário dessas mães, é importante a referência ao tempo médio de gestação despendido em uma gravidez biológica. Mesmo acelerada, a adaptação foi progressiva, passo a passo. "Que a adaptação assim de ir pegar pra fisio e voltar, não deu duas semanas. Foi uma semana, no sábado eles deixaram a gente pegar às sete da manhã e entregar às cinco. Ai foram todos os dias assim" (Adriana).

As participantes contam que receberam diretamente a guarda definitiva, em vez da provisória, e que o documento da guarda saiu em nome das duas. Nesse processo, comentam que foram tratadas com naturalidade no Fórum e que estranharam não receberem visita domiciliar.
A principio, a gente achava que a guarda ia sair apenas no meu nome, porque uma coisa assim, eles perguntam se a gente tem condição financeira, mas perguntar e investigar são coisas diferentes, né? Ninguém investigou... com a gente, não sei se foram ver imposto de renda, essas coisas, mas não investigaram com a gente. A gente achava muito estranho. (Tarsila)

O casal manifesta seu estranhamento porque o andamento do processo não correspondeu às expectativas iniciais de morosidade do processo de avaliação. Há um misto de espanto e incredulidade nas reações das duas mulheres. Adriana conta: "Ninguém foi em casa". Ao que Tarsila emendou, quase indignada: "Como que... do Fórum ninguém foi em casa, só as psicólogas do B foram ver onde a gente morava. E até hoje, faz um ano e meio, ninguém veio. Converso com o psicólogo, mas... não ficam sabendo assim como...". Adriana se recordou de uma fala de outra profissional: "A advogada comenta que eles investigam rede social, investigam imposto, essas coisas eles vão investigando por fora, mas [...] Visita a gente não teve nenhuma". E Tarsila completa:

A gente achava que ia sair no meu nome, por causa de tudo isso, da parte financeira, né? Mas, quando a gente viu, saiu no meu nome e no dela. E saiu a guarda definitiva, que normalmente em adoção sai uma guarda provisória depois de [...] seis meses tem que renovar, tem todo o processo de psicólogo de novo, e isso vai indo por uns três anos, né? Hoje, o nosso saiu já com a definitiva, que já é em processo de adoção.

Assim sendo, a guarda foi concedida em nome das duas mulheres, reconhecidas pelo documento legal como mães. $O$ fato de a certidão da criança ser emitida em nome de duas pessoas do mesmo sexo só se tornou uma realidade há pouco tempo. A jurisprudência foi criada em meados da década passada (Uziel, 2007). Os fatos descritos aconteceram em 2012. Por fim, Adriana questionou os profissionais do Fórum a respeito dos atuais critérios para adoção.

E no Fórum, trataram com a maior naturalidade. Tipo assim, foi tranquilo. A gente até perguntou: "Mas, hoje em dia, está mais tranquilo pras pessoas? Quais são os critérios?" Ai a psicóloga comentou que não tem mais aquele critério que tem que ser casado, com tantos anos de casamento e tal, qualquer pessoa, se tem uma condição e tenha vontade, tudo o mais pra adotar, elas podem. Desde que elas tenham... é, a parte psicológica boa, financeira, tudo o mais. Não que uma pessoa que seja pobre não possa adotar também, desde que ela tenha condições de criar a criança. Condições para tirar a criança da rua e pra colocar numa família que tem condições de, pelo menos, dar o básico para a criança. Mas eles falaram que não tem mais tanta burocracia com relação a essa parte de... tipo, a mãe solteira não poder adotar, casal gay, mulher solteira... não tem essa, não. (Adriana)

No relato de Adriana acerca dos critérios do Fórum, a possibilidade de adoção não está restrita aos casais 
heterossexuais; pessoas solteiras e homossexuais também podem ser aceitas para adotar. O critério primordial é oferecer condições (tanto financeiras como emocionais) que favoreçam o bem-estar da criança. Por outro lado, em vários momentos da entrevista nota-se a percepção de que a condição socioeconômica privilegiada do casal e os déficits de desenvolvimento da criança podem ter sido os fatores definidores para a mudança repentina que se observou, dando-se lugar à surpreendente agilidade com que o processo legal se desenrolou. Pode-se indagar, a partir dessas evidências: como teria sido se o casal adotante e a criança disponível para adoção não apresentassem essas condições especiais? Será que os preconceitos que atravessam as relações entre os profissionais da área e as pessoas que se candidatam à adoção tendem a ser mitigados quando a criança tem um curso de desenvolvimento francamente desfavorecido? Estes são pontos relevantes que precisam ser mais investigados por estudos futuros e que devem ser considerados no planejamento de intervenções específicas no contexto da adoção na interface com a diversidade sexual. Quando se trata de processos de adoção por homossexuais, as concepções no cenário jurídico resultam da desinformação e/ou dos estereótipos que demonstram que as decisões dos profissionais não refletem os pensamentos contemporâneos e científicos sobre o fato. A escassez de pesquisas na área e as ambiguidades na interpretação da legislação contribuem para o fomento das contradições que os psicólogos e outros profissionais do judiciário apresentam tanto em relação à concepção de homossexualidade quanto em relação à homoparentalidade (Farias \& Maia, 2009).

Os estudos na área apontam alguns pontos críticos que funcionam como nós a serem desatados no decorrer do processo de adoção em nosso país: a "invisibilidade" da família de origem; a recorrente violação de direitos da criança à convivência familiar; falhas na rede de proteção; significações sobre o que supostamente seria uma "família saudável" para a criança a ser adotada; e o papel das concepções sobre apego que permeiam o campo da adoção (Rossetti-Ferreira et al., 2012). Entretanto no âmbito nacional, ainda são escassas as pesquisas sobre adoção por indivíduos ou casais homossexuais que levem em consideração as peculiaridades da relação amorosa e conjugal dos pares homoafetivos (Almeida, 2012; Amazonas, Veríssimo, \& Lourenço, 2013).

\section{CONSIDERAÇÕES FINAIS}

O estudo realizado revela que o percurso sinuoso rumo à adoção foi marcado por dois momentos distintos. Primeiramente, nota-se a luta do casal de mulheres para afirmar a legitimidade de seu desejo e de seu direito de se tornarem mães pela via da adoção. Nesse processo as mulheres depararam-se com profissionais despreparados ou com convicções baseadas em preconceitos ou crenças infundadas sobre a homossexualidade e a razoabilidade de uma pessoa homossexual exercer o papel parental. Diante dos entraves encontrados inicialmente, dos "nãos" recebidos e, de certo modo, do preconceito internalizado, a estratégia de se submeterem ao procedimento de fertilização in vitro chegou a ser cogitada, mas a ideia logo foi abandonada em função do elevado custo que esse tipo de tratamento implica. O desejo de adoção foi gradualmente se fortalecendo, mas o fator que o impulsionou decididamente foi o encontro com uma criança (Nísia), que chamou a atenção do casal devido à fragilidade de sua condição física e à situação de desamparo em que ela se encontrava. O que despertou nas futuras mães o desejo de cuidar dela, dar-lhe um lar e o direito a um futuro.

Em um segundo momento, o que vimos foi a surpresa crescente do casal com as facilidades encontradas para a conclusão da adoção. A obstinação das parceiras foi decisiva para que houvesse uma reviravolta no processo. Ao se compararem com outras histórias de adoção e medirem suas próprias expectativas de encontrarem barreiras quase que intransponíveis pelo fato de não serem um casal convencional, Tarsila e Adriana se surpreenderam com os rumos que o processo acabou tomando. Certas etapas foram queimadas: critérios restritivos foram nitidamente afrouxados e a guarda que seria provisória foi concedida pelo juiz como definitiva. Tudo conspirava para que o processo fosse acelerado, o que é incomum nos casos de adoção de modo geral, mas não em casos de crianças com deficiências, independentemente da orientação sexual dos adotantes. É como se essa característica da criança (debilitada, desnutrida, com prognóstico reservado por conta da microcefalia) houvesse se sobrepujado aos outros possíveis óbices, como o fato de ela ser reivindicada por um casal lésbico. O desfecho do périplo foi altamente positivo. O casal se orgulha do caminho percorrido para iniciar a experiência da parentalidade. E a criança correspondia aos esforços e investimentos maternos, uma vez que estava se desenvolvendo excepcionalmente bem, considerando as circunstâncias adversas do período inicial de vida.

Novas investigações são necessárias para esclarecer se o caso colocado em relevo no presente estudo representa a regra ou a exceção no cenário brasileiro da adoção por casais homoafetivos. É preciso explorar as vivências das famílias adotantes no contexto homoafetivo, inclusive em relação à avaliação psicossocial realizada pela equipe técnica do Fórum. Ressalta-se também a necessidade de promover intervenções familiares, que possibilitem avaliar e atuar as dificuldades apresentadas, a partir de uma perspectiva ampla e integradora. Ao acolher uma criança, as mães a recebem com a bagagem de dores e sofrimentos de seu passado. É preciso ajudar a criança a elaborar os conteúdos psíquicos vivenciados a partir das experiências de ruptura precoce 
dos vínculos com os pais biológicos, de modo a poder ressignificar suas relações familiares.

O presente estudo tem algumas limitações evidentes, como a delimitação dos participantes (uma única família) e o tipo de delineamento (estudo de caso), que gera a impossibilidade de generalização dos dados. No entanto, os resultados sistematizados ajudam a esmiuçar os meandros e constrangimentos adicionais a que estão sujeitas as pessoas de orientação sexual divergente da heteronormatividade que desejam adotar. Nessa perspectiva, os dados são alvissareiros porque revelam a importância de realizar estudos de casos envolvendo todo o grupo familiar, para que se conheça a problemática a partir de uma dimensão situada e integrada. Nesse contexto, um olhar isolado, como o dirigido apenas à criança, seria forçosamente incompleto e com poucas chances de ser bem-sucedido.

Destaca-se também a necessidade de novas pesquisas que investiguem as melhores estratégias de intervenção para as famílias homoparentais e para casais de mesmo sexo que pretendem adotar, tendo em vista que não foram encontrados estudos que aprofundem essa temática na literatura brasileira. Há literatura, por exemplo, sobre grupos de apoio para casais pretendentes à adoção (Scorsolini-Comin \& Santos, 2008), entretanto não são programas ou estratégias direcionadas aos casais homoafetivos. Assim, as implicações dos achados da presente pesquisa são consideráveis para compor o planejamento de políticas públicas e práticas sociais nesse campo de investigação e atuação profissional.

\section{REFERÊNCIAS}

Almeida, M. R. (2012). Os processos subjetivos no acolhimento e na adoção de crianças por casal homoafetivo: um estudo de caso (Tese de Doutorado). Programa de Pós-Graduação em Psicologia, Universidade de São Paulo, São Paulo, SP, Brasil.

Amazonas, M. C. L. A., Veríssimo, H. V., \& Lourenço, G. O. (2013). A adoção de crianças por gays. Psicologia \& Sociedade, 25(3), 631-641.

Araújo, L. F., Oliveira, J. S. C., Sousa, V. C., \& Castanha, A. R. (2007). Adoção de crianças por casais homoafetivos: um estudo comparativo entre universitários de Direito e de Psicologia. Psicologia \& Sociedade, 19(2), 95-102.

Brasil, Ministério da Saúde. (2012). Resolução número 466, de 12 de dezembro de 2012 do Conselho Nacional de Saúdel MS. Recuperado de conselho.saude.gov.br/resolucoes/2012/ Reso466.pdf

Braun, V., \& Clarke, V. (2006). Using thematic analysis in psychology. Qualitative Research in Psychology, 3(2), 77-101.

Campos, N. M. V., \& Costa, L. F. (2004). A subjetividade presente no estudo psicossocial da adoção. Psicologia: Reflexão $e$ Crítica, 17(1), 95-104.

Cecílio, M. S., Scorsolini-Comin, F., \& Santos, M. A. (2013). Produção científica sobre adoção por casais homossexuais no contexto brasileiro. Estudos em Psicologia (Natal), 18(3), 507-516. Disponível em: http://www.scielo.br/pdf/epsic/ v18n3/11.pdf.

Corrêa, M. E. C. (2012). Duas mães?Mulheres lésbicas e maternidade (Tese de Doutorado). Programa de Pós-Graduação em Saúde Materno Infantil, Universidade de São Paulo, São Paulo, SP, Brasil.

Conselho Nacional de Justiça. (2015). Programa de apadrinhamento afetivo começa a ser implantado em SP. Recuperado de www. cnj.jus.br/c36j

Costa, L. F., \& Campos, N. M. V. (2003). A avaliação psicossocial no contexto da adoção: vivência das famílias adotantes. Psicologia: Teoria e Pesquisa, 19(3), 221-230.

Farias, M. O., \& Maia, A. C. B. (2009). Adoção por homossexuais A familia homoparental sob o olhar da Psicologia Jurídica. Curitiba, PR: Juruá.

Fonseca, C. (2002). Caminhos da adoção. São Paulo, SP: Cortez.

Goldberg, A. E., Kinkler, L. A., Moyer, A. M., \& Weber, E. (2014). Intimate relationship challenges in early parenthood among lesbian, gay, and heterosexual couples adopting via the child welfare system. Professional Psychology: Research and Practice, 45(4), 221-230.

Goldberg, A. E., \& Smith, J. Z. (2011). Stigma, social context, and mental health: lesbian and gay couples across the transition to adoptive parenthood. Journal of Counseling Psychology, $58(1), 139-150$.

Golombok, S. (2015). Modern families: Parents and children in new family forms. Cambridge, UK: Cambridge University Press.

Golombok, S., Mellish, L., Jennings, S., Casey, P., Tasker, F., \& Lamb, M. E. (2014). Adoptive gay father families: parent-child relationship and children's psychological adjustment. Child Development, 85(2), 456-468.

Golombok, S., Perry, B., Burston, A., Murray, C., Mooney-Somers, J., Stevens, M., \& Golding, J. (2003). Children with lesbian mothers: A community study. Developmental Psychology, 39(1), 20-33.

Haag, C. (2007). Um é pouco, dois é bom: estudos desmistificam preconceitos sobre famílias de pais homossexuais. Pesquisa FAPESP, 132, 86-89.

Lauriano, C., \& Duarte, N. (2011). Censo 2010 contabiliza mais de 60 mil casais homossexuais. Recuperado de g1.globo.com/ brasil/noticia/2011/04/censo-2010contabiliza-maisde-60-milcasais-homossexuais.html

Lévi-Strauss, C. (1982). As estruturas elementares de parentesco (M. Ferreira, trad., $3^{\mathrm{a}}$ ed.). Petrópolis, RJ: Vozes.

Levy, L., \& Féres-Carneiro, T. (2001). Da maternidade impossível ao possível da filiação: Sobre o desejo de adoção. Tempo Psicanalítico, 33(1), 77-88.

Manzi-Oliveira, A. B. (2009). Adoção por casais homoafetivos: Relato de seus protagonistas. Monografia de Conclusão do Programa Optativo de Bacharelado em Psicologia, Universidade de São Paulo, Ribeirão Preto, SP, Brasil.

Martinez, A. L. M. (2011). Considerações sobre o psicodinamismo de famílias homoparentais femininas: Uma visão psicanalítica (Tese de Doutorado). Programa de Pós-Graduação em Psicologia, Universidade de São Paulo, Ribeirão Preto, SP, Brasil.

Moscheta, M. S. (2004). Construindo a diferença: a intimidade conjugal em casais de homens homossexuais (Dissertação de Mestrado). Programa de Pós-Graduação em Psicologia, Universidade de São Paulo, Ribeirão Preto, SP, Brasil.

Nascimento, A. C. A. (2006). Resiliência e sensibilidade materna na interação mãe-criança com fissura labiopalatina (Tese de Doutorado). Programa de Pós-Graduação em Psicologia, Pontifícia Universidade Católica, Campinas, SP, Brasil.

Oliveira, D. B. B. (2011). Famílias contemporâneas: As voltas que o mundo dá e o reconhecimento jurídico da homoparentalidade. Curitiba, PR: Juruá.

Otuka, L. K., Scorsolini-Comin, F., \& Santos, M. A. (2012). Adoção suficientemente boa: experiência de um casal com filhos biológicos. Psicologia: Teoria e Pesquisa, 28(1), 55-63. 
Passos, M. C. (2005). Homoparentalidade: Uma entre outras formas de ser família. Psicologia Clínica, 17(2), 31-40.

Perosa, G. B., Silveira, F. C. P., \& Canavez, I. C. (2008). Ansiedade e depressão de mães de recém-nascidos com malformações visíveis. Psicologia: Teoria e Pesquisa, 24(1), 29- 35.

Pozzetti, V. C., \& Silva, U. A. (2013). A resolução n ${ }^{\circ} 175$ do CNJ e os requisitos para a celebração do casamento. Scientia Iuris, 17(2), 107-130.

Rodriguez, B. C. (2012). A representação parental de casais homossexuais masculinos (Dissertação de Mestrado). Programa de Pós-Graduação em Psicologia, Universidade de São Paulo, São Paulo, SP, Brasil.

Rodriguez, B. C., \& Paiva, M. L. S. C. (2009). Um estudo sobre o exercício da parentalidade em contexto homoparental. Vínculo, 6(1), 13-25.

Rossetti-Ferreira, M. C., Almeida, I. G., Costa, N. R., Guimarães, L. A., Mariano, F. N., Teixeira, S. C. P., \& Serrano, S. A. (2012). Acolhimento de crianças e adolescentes em situações de abandono, violência e rupturas. Psicologia: Reflexão $e$ Crítica, 25(2), 390-399.

Scorsolini-Comin, F., \& Santos, M. A. (2008). Aprender a viver é o viver mesmo: o aprendizado a partir do outro em um grupo de pais candidatos à adoção. Vínculo, 5, 115-130.

Secretaria Especial de Comunicação Social do Senado Federal. (2013 maio). Adoção: mudar um destino. Em discussão!, 4(15). Recuperado de www12.senado.leg.br/jornal/revistaem-discussao

Silva, D. A. (2013). Enfim mães! Da experiência da reprodução assistida à experiência da maternidade lésbica (Dissertação de Mestrado). Programa de Pós-Graduação em Psicologia Social, Universidade do Estado do Rio de Janeiro, Rio de Janeiro, RJ, Brasil.

Silva, E. R. A. (Org.). (2004). O direito à convivência familiar e comunitária: os abrigos para crianças e adolescentes no Brasil. Brasília, DF: Fundação Instituto de Pesquisa Econômica Aplicada.
Silva, F. H. O. B., \& Cavalcante, L. I. C. (2015). Rotinas familiares de crianças com necessidades especiais em família adotiva. Psicologia Teoria e Pesquisa, 31(2), 173-180.

Sonego, J. C., \& Lopes, R. C. S. (2009). A experiência da maternidade em mães adotivas. Aletheia, 29, 16-26.

Stake, R. E. (2005). Qualitative case studies. In N. K. Denzin \& Y. S. Lincoln (Orgs.), The SAGE handbook of qualitative research (3rd ed., pp. 443-466). London: Sage.

Supremo Tribunal Federal. (2013). Resolução sobre casamento civil entre pessoas do mesmo sexo é aprovada pelo Conselho Nacional de Justiça. Brasília. Recuperado de http://www2. stf.jus.br/portalStfInternacional/cms/destaquesNewsletter. php?sigla $=$ new sletterPortalInternacionalDestaques\&idCont eudo $=238515$.

Teixeira Filho, F. S., Toledo, L. G., \& Godinho, P. H. (2007). A homofobia na representação de mães heterossexuais sobre a homoparentalidade. In M. Grossi et al. (Orgs.), Conjugalidades, parentalidades e identidades lésbicas, gays e travestis (pp. 301318). Rio de Janeiro: Garamond.

Tombolato, M. A., Maia, A. C. B., Uziel, A. P., \& Santos, M. (2018). Prejudice and discrimination in the everyday life of same-sex couples raising children. Estudos de Psicologia (Campinas), 35(1), 111-122.

Torres, A. F. (2009). Adoção nas relações homoparentais. São Paulo: Atlas.

Uziel, A. P. (2007). Homossexualidade e adoção. Rio de Janeiro: Garamond.

Vieira, R. S. (2011). Homoparentalidade: Estudo psicanalitico sobre papéis e funções parentais em casais homossexuais com filhos (Dissertação de Mestrado). Programa de Pós-Graduação em Psicologia, Universidade de São Paulo, São Paulo.

Weber, L. N. D. (2004). Aspectos psicológicos da adoção (2a ed.). Curitiba, PR: Juruá.

Zambrano, E. (2006). O direito à homoparentalidade: Cartilha sobre as familias constituídas por pais homossexuais. Porto Alegre, RS: Vênus. 